\title{
Analisis Pelaksanaan Medical Check Up (MCU) pada Pegawai Rumah Sakit Islam Jakarta Pondok Kopi Tahun 2016
}

\author{
Slamet Sudi Santoso ${ }^{1}$, Andriyani ${ }^{2}$ \\ ${ }^{1}$ Program Studi Kedokteran, Fakultas Kedokteran dan Kesehatan, Universitas Muhammadiyah Jakarta \\ ${ }^{2}$ Program Studi Kesehatan Masyarakat, Fakultas Kedokteran dan Kesehatan, Universitas Muhammadiyah Jakarta \\ Jl. KH. Ahmad Dahlan, Ciputat, Cirendeu, Banten 15419 \\ Email: santohope2016@gmail.com
}

\begin{abstract}
ABSTRAK
Dalam Undang-undang Nomor 23 Tahun 1992 tentang Kesehatan, pasal 23 menyatakan bahwa upaya Kesehatan dan Keselamatan Kerja (K3) harus dilakukan di semua tempat kerja, yang memiliki pegawai paling sedikit 10 orang. RSIJ Pondok Kopi (RSIJPK) adalah salah satu Rumah Sakit Islam di Jakarta yang memiliki upaya preventif untuk meningkatkan produktivitas karyawan melalui skrining kesehatan pegawai atau yang disebut dengan Medical Check-Up (MCU) yang dipantau oleh Unit Manajemen Risiko (Manrisk). Berdasarkan pengamatan tersebut, dicatat bahwa pelaksanaan MCU, belum sesuai sebagaimana mestinya, berdasarkan Permenaker No. 02 / Men / 1980. Penelitian ini merupakan penelitian kualitatif. Teknik yang digunakan dalam pengumpulan data adalah observasi lapangan, review dokumen, dan wawancara mendalam. Data yang terkumpul kemudian dianalisis dengan menggunakan teori sistem yaitu input, proses, output, umpan balik, dan lingkungan. Berdasarkan penelitian ini, diketahui bahwa masalah terjadi pada input dan proses, pemeriksaan kesehatan sebelum bekerja dan berkala, adalah kurangnya dokter dan klinik khusus untuk MCU, dan ini menghambat penerapan MCU. Saran dalam penelitian ini adalah sebaiknya ada dokter bersertifikat Hiperkes di RSIJPK dan klinik khusus untuk implementasi MCU. Selain pemeriksaan kesehatan khusus, disarankan agar pemeriksaan kepada karyawan yang akan dirotasi ke tempat lain untuk mengetahui kondisi kesehatan karyawan sebelum bekerja di tempat kerja yang baru, dan untuk pemeriksaan kesehatan berkala, disarankan agar semua karyawan diberikan hasil pemeriksaan sebagai patokan bagi karyawan untuk menjaga kesehatannya.
\end{abstract}

Kata kunci: Pemeriksaan Kesehatan (MCU), Kualitatif, Masukan, Proses, Keluaran

\section{Analysis of Implementation of Employees's Medical Check Up (MCU) on Islamic Hospital Jakarta Pondok Kopi}

\begin{abstract}
In Act No. 23 of 1992 on Health, article 23 stated that the efforts of K3 must be held in all places of employment, that has employee at least 10 people. RSIJ Pondok Kopi is one of the Islamic Hospital in Jakarta that has a preventive effort to improve employee's productivity through employee health screening or called by Medical Check-Up (MCU) which is monitored by the Risk Management Unit (Manrisk). Based on the observation, noted that the implementation of the MCU, has not appropriate as it should be, based on Permenaker No. 02/Men/1980. This research is a qualitative research. Techniques used in data collection were field observations, review of documents, and in-depth interviews. The collected data was then analyzed using systems theory that is input, process, output, feedback, and the environment. Based on this research, it is known that the problem occurs in the input and process, medical examination before work and periodic, were the lack of doctors and specialized clinics for MCU, and it obstracted the implementation of MCU. There were also another factors that cause the implementation of MCU was not running well. Suggestions in this research is there should be a Hiperkes certified doctor in RSIJPK and specialized clinics for
\end{abstract}


implementation of MCU. In addition to special medical examinations, it is suggested that examination to the employees who will be rotated to determine the health condition of the employee prior to working in their newly workplace, and for periodic medical examinations, it is recommended that all employees are given the results of the examination as a benchmark for employees to maintain their health.

Keywords: Medical Check-Up (MCU), Qualitative, Input, Process, Output

\section{Pendahuluan}

Rumah Sakit (RS) merupakan salah satu tempat untuk meningkatkan derajat kesehatan masyarakat. Berdasarkan Kepmenkes RI No. 1204/Menkes/SK/X/2004 tentang Persyaratan Kesehatan Lingkungan Rumah Sakit dinyatakan, bahwa rumah sakit sebagai sarana pelayanan kesehatan tempat berkumpulnya orang sakit maupun orang sehat yang memungkinkan terjadinya pencemaran lingkungan dan gangguan kesehatan. Kegiatankegiatan yang dilakukan dituntut untuk selalu dalam kondisi dan keadaan yang saniter serta sesuai dengan peraturan - peraturan yang berlaku. ${ }^{1}$

Dalam Undang-Undang Nomor 23 Tahun 1992 tentang Kesehatan, Pasal 23 dinyatakan bahwa upaya K3 harus diselenggarakan di semua tempat kerja, khususnya tempat kerja yang mempunyai risiko bahaya kesehatan, mudah terjangkit penyakit atau mempunyai pegawai paling sedikit 10 orang. $^{2}$ Merujuk dari hal tersebut, Rumah Sakit termasuk dalam kriteria tempat kerja dengan berbagai macam ancaman bahaya baik yang berdampak maupun tidak pada kesehatan. Bukan hanya para pekerja Rumah Sakit, melainkan pada pasien maupun pengunjung Rumah Sakit. Sehingga sudah seharusnya pihak pengelola RS menerapkan upaya-upaya K3 di RS.

Data tahun 2014, 4\% perawat di USA adalah petugas medis. Laporan yang dibuat oleh The National Safety Council (NSC), ada petugas medis mengalami absenteisme yang diakibatkan oleh PAK dan injury yaitu sebanyak $41 \%$. Angka tersebut jauh lebih besar dibandingkan dengan sektor industri lainnya. ${ }^{3}$ Laporan lainnya yakni di Israel, angka prevalensi cedera punggung tertinggi pada perawat $(16,8 \%)$ dibandingkan pekerja sektor industri lain. Di Australia, dari 813 perawat, $87 \%$ diantaranya mengalami low back pain. Di Amerika Serikat, terjadi insiden cedera musculoskeletal 4,62/100 perawat per tahun. Cedera punggung menghabiskan biaya kompensasi terbesar, yaitu lebih dari 1 milliar dollar per tahun.

Di Indonesia, data penelitian sehubungan dengan bahaya-bahaya di RS belum tergambar dengan jelas, namun diyakini bahwa banyak keluhan-keluhan dari para petugas di RS, sehubungan dengan bahaya - bahaya yang ada di RS (Pedoman Manajemen K3) di Rumah Sakit. $^{4}$

Selain itu, Gun memberikan catatan bahwa terdapat beberapa kasus penyakit kronis yang diderita petugas RS, yakni hipertensi, varises, anemia (kebanyakan wanita), penyakit ginjal dan saluran kemih (69\% wanita), 
dermatitis dan urtikaria (57\% wanita) serta nyeri tulang belakang dan pergeseran discus invertebrae. Ditambahkan juga bahwa terdapat beberapa kasus penyakit akut yang diderita petugas RS lebih besar 1,5 kali dari petugas atau pekerja lain, yaitu penyakit infeksi dan parasit, saluran pernafasan, saluran cerna dan keluhan lain, seperti sakit telinga, sakit kepala gangguan saluran kemih, masalah kelahiran anak, gangguan pada saat kehamilan, penyakit kulit dan sistem otot dan tulang rangka (Pedoman Manajemen Kesehatan dan Keselamatan Kerja (K3) di Rumah Sakit. ${ }^{4}$

Sedangkan dari hasil penelitian Trisilawati, di RSUD Dr. Haryoto Lumajang terdapat angka kejadian KAK (Kecelakaan Akibat Kerja) yang cukup besar yaitu 57,83\% dan PAK (Penyakit Akibat Kerja) sebesar 21,69\%.5 Masalah K3 tersebut terjadi karena berbagai sebab diantaranya adalah pengelolaan data dan informasi yang kurang baik terhadap setiap kejadian KAK dan PAK tersebut. Selain itu juga disebabkan karena sebagian besar tenaga RS tidak pernah mengikuti penyuluhan, diklat atau seminar K3 sehingga sebagian besar dari mereka tidak tahu bagaimana upaya penanggulangan kejadian KAK dan PAK maupun upaya penanggulangan masalah K3 lainnya.

Melihat hal tersebut, peneliti bermaksud untuk meneliti salah satu Rumah Sakit (RS) yang ada di Jakarta yaitu RSIJPK, dimana RS ini merupakan salah satu Rumah Sakit yang menerapkan K3 Rumah Sakit. Berdasarkan data yang telah peneliti sebutkan diatas, Rumah Sakit merupakan suatu industri jasa yang tidak terlepas dari risiko Penyakit Akibat Kerja (PAK), Penyakit Akibat Hubungan Kerja (PAHK), maupun Kecelakaan Akibat Kerja (KAK) yang berpengaruh terhadap penurunan produktivitas kerja pegawai.

Berdasarkan hasil pengamatan, penulis menemukan masalah dalam pelaksanaan MCU, yaitu belum berjalan optimal dan sesuai dengan peraturan dalam melaksanakan MCU. Penulis mengamati hasil MCU pegawai RSIJ Pondok Kopi masih banyak yang belum melaksanakan MCU, selain itu pelaksanaan MCU juga masih belum sesuai dengan yang seharusnya yaitu berdasarkan Permenaker No. 02/Men/1980 tentang Pemeriksaan Kesehatan Tenaga Kerja dalam Penyelenggaraan Keselamatan Kerja. ${ }^{6}$

\section{Metode Penelitian}

Penelitian ini merupakan penelitian kualitatif untuk mengetahui gambaran pelaksanaan pemeriksaan kesehatan pegawai (MCU), faktor - faktor apa saja yang mendukung dan menghambat RS dalam proses pelaksanaan MCU, serta bagaimana mengatasi hambatan tersebut. Identifikasi bahaya maupun pengambilan data dan informasi dilakukan dengan melakukan wawancara mendalam kepada informan, observasi lapangan dan review dokumen. Pendekatan kualitatif ini menuntut peneliti untuk bertindak sebagai instrumen utama dalam penelitian. Penelitian ini dilaksanakan di RSIJ Pondok Kopi, di Jakarta. 


\section{Hasil dan Pembahasan}

Tabel 1. Hasil Penelitian Kompetensi Tenaga Kesehatan

\begin{tabular}{|c|c|c|c|}
\hline & $\begin{array}{c}\text { Hasil } \\
\text { Observasi }\end{array}$ & Hasil Telaah Dokumen & Hasil Wawancara \\
\hline \multirow[t]{2}{*}{$\begin{array}{l}\text { Pemeriksaan } \\
\text { Kesehatan } \\
\text { Sebelum } \\
\text { Bekerja }\end{array}$} & $\begin{array}{l}\text { Tidak dilakukan } \\
\text { observasi }\end{array}$ & $\begin{array}{l}\text { Kompetensi tenaga kesehatan yang } \\
\text { bertugas untuk pemeriksaan fisik } \\
\text { pada calon pegawai belum memenuhi } \\
\text { syarat sesuai dengan yang telah } \\
\text { ditetapkan oleh }\end{array}$ & \multirow{2}{*}{$\begin{array}{l}\text { Kompetensi tenaga kesehatan yang bertugas } \\
\text { untuk pemeriksaan fisik pada calon pegawai } \\
\text { belum memenuhi syarat yang telah ditetapkan } \\
\text { oleh Permenakertrans No. 02. Tahun } 1980 \\
\text { tentang Pemeriksaan Kesehatan dan Pedoman } \\
\text { Pelayanan Medik di Klinik Departemen dan } \\
\text { Perusahaan Kemenkes RI Tahun } 2008 \text {. }\end{array}$} \\
\hline & & $\begin{array}{l}\text { Permenakertrans No. 02. Tahun } 1980 \\
\text { tentang Pemeriksaan Kesehatan dan } \\
\text { Pedoman Pelayanan Medik di Klinik } \\
\text { Departemen dan Perusahaan } \\
\text { Kemenkes RI Tahun 2008. Hal ini } \\
\text { dikarenakan belum ada Dokter K3 } \\
\text { yang bertugas di RSIJPK }\end{array}$ & \\
\hline $\begin{array}{l}\text { Pemeriksaan } \\
\text { Kesehatan } \\
\text { Berkala }\end{array}$ & $\begin{array}{l}\text { Tidak dilakukan } \\
\text { observasi }\end{array}$ & Tidak dilakukan telaah dokumen & $\begin{array}{l}\text { Kompetensi tenaga kesehatan yang bertugas } \\
\text { untuk pemeriksaan kesehatan berkala kepada } \\
\text { pegawai adalah tanggung jawab dari pihak } \\
\text { Manajemen Risiko (Manris) bekerja sama } \\
\text { dengan Bagian MCU }\end{array}$ \\
\hline $\begin{array}{l}\text { Pemeriksaan } \\
\text { Kesehatan } \\
\text { Khusus }\end{array}$ & $\begin{array}{l}\text { Tidak dilakukan } \\
\text { observasi }\end{array}$ & Tidak dilakukan telaah dokumen & $\begin{array}{l}\text { Kompetensi tenaga kesehatan yang bertugas } \\
\text { untuk pemeriksaan kesehatan khusus kepada } \\
\text { pegawai adalah tanggung jawab dari pihak } \\
\text { Manris bekerja sama dengan MCU. }\end{array}$ \\
\hline
\end{tabular}

Menurut hasil wawancara dengan informan yang terdiri dari kepala bagian Manris dan kepala bagian MCU yaitu Ibu NA dan Bapak SY, untuk pelaksanaan MCU sebelum bekerja dilakukan dibagian $\mathrm{MCU}$ dan yang melakukan pemeriksaan adalah dokter umum. Berikut ini kutipan hasil wawancara dengan kepala bagian Manris:

“... Seharusnya sih yang bener ya Dokter K3 yang melaksanakan MCU, tapi dokter K3 disini masih disekolahkan, selebihnya yang melakukan ya dokter umum dibantu orangorang bagian MCU..."

Berikut ini kutipan hasil wawancara dengan kepala bagian MCU:

“... yang menentukan apa-apanya sih dari bagian Manris, kita itu ibarat pelaksana, jadi ketika Manris meminta ke Rumah Sakit, Dokter, ya oleh Rumah Sakit dikasihnya Dokter Umum. “

Menurut Silalahi, sumber daya manusia merupakan elemen penting dari lingkungan dalam dan merupakan aset penting dari organisasi dibandingkan dengan elemen lingkungan dalam lainnya. ${ }^{7}$ Secara sederhana dapat dinyatakan, bahawa sumber daya manusialah yang membuat sumber- sumber lain dari suatu organisasi bekerja. Manusia menjadi motor penggerak aktivitas manajerial.

Suhendra menjabarkan bahwa salah satu persyaratan dalam proses rekrutmen adalah kecakapan, mengenai kecakapan ada tiga hal pokok yang harus diperhatikan: ${ }^{8}$ 
- Pendidikan, misalkan beban tugas dan kewenangan jabatan tersebut memerlukan kapasitas pendidikan tertentu, apakah cukup tamatan SD, SMP, SMA, atau diperlukan seorang sarjana untuk mengisinya.

- Kualifikasi kerja, apakah perlu pengalaman sebagai magang, atau sertifikat lulus pendidikan tertentu. Pengalaman, syarat pengalaman pekerjaan dalam bidang apa dan berapa lama agar calon pegawai itu dapat bekerja dengan baik.

Pemeriksaan kesehatan bagi pegawai dilaksanakan oleh dokter, di dalam Permenakertrans No. 02 Tahun 1980 tentang pemeriksaan kesehatan, dokter adalah dokter yang ditunjuk oleh pengusaha yang telah memenuhi syarat sesuai dengan Peraturan Menteri Tenaga Kerja dan Transmigrasi dan Koperasi No. Per/10/Men/1976 dan syarat syarat lain yang dibenarkan oleh Direktur Jenderal Pembinaan Hubungan Perburuhan dan Perlindungan Tenaga Kerja. ${ }^{6}$

Dalam Permenakertranskop No. Per/01/Men/1976 Pasal 1, setiap perusahaan diwajibkan untuk mengirimkan setiap dokter perusahaannya untuk mendapatkan latihan dalam bidang Hygiene Perusahaan Kesehatan dan Keselamatan Kerja. Dalam pasal 2 dijelaskan bahwa yang dimaksud dokter perusahaan adalah setiap dokter yang ditunjuk atau bekerja di perusahaan yang bertugas dan atau bertanggung jawab atas Hygiene Perusahaan Keselamatan dan Kesehatan Kerja.

Berdasarkan hasil wawancara mendalam dan telaah dokumen, kompetensi dari tenaga kesehatan untuk pemeriksaan kesehatan sebelum bekerja di RSIJPK masih belum sesuai dengan kriteria yang telah disebutkan di atas. Kompetensi dokter yang seharusnya dipenuhi yaitu dokter perusahaan telah memiliki sertifikat pelatihan Hiperkes, mempunyai surat tanda registrasi dan surat izin praktik, dan mampu melaksanakan pelayanan medik sesuai dengan kompetensi dan kewenangannya.

\section{Proses}

a. Pemeriksaan Kesehatan Sebelum Bekerja Peneliti melakukan telaah dokumen terkait dengan proses pemeriksaan kesehatan sebelum bekerja. Dokumen yang digunakan sebagai pedoman dalam pelaksanaan pemeriksaan kesehatan sebelum bekerja adalah Standard Operating Procedures (SOP) pemeriksaan kesehatan. Di dalam SOP, terdapat langkahlangkah yang harus dilaksanakan dalam proses pemeriksaan kesehatan sebelum bekerja.

Berdasarkan hasil wawancara mendalam dengan informan utama, pemeriksaan kesehatan sebelum bekerja dilakukan oleh calon pegawai di bagian MCU. Pemeriksaan laboratorium dilakukan di laboratorium RSIJPK. Berikut adalah kutipan hasil wawancara dengan informan kunci:

“...nah, kalau untuk pelaksanaannya, biasanya yang terkait pemeriksaan fisik calon pekerja, dilakukan di bagian MCU lalu ke klinik umum, mata, dan/ atau gigi. Kalau untuk tes labnya, di lab RS. Gitu..." (EI) 
Berdasarkan hasil wawancara mendalam dengan informan kunci, kepala bagian Manris mengungkapkan bahwa pemeriksaan kesehatan sebelum bekerja terdiri dari pemeriksaan fisik, rontgen, buta warna, dan laboratorium. Berikut ini adalah alur pemeriksaan kesehatan sebelum bekerja bagi calon pegawai di RSIJPK.

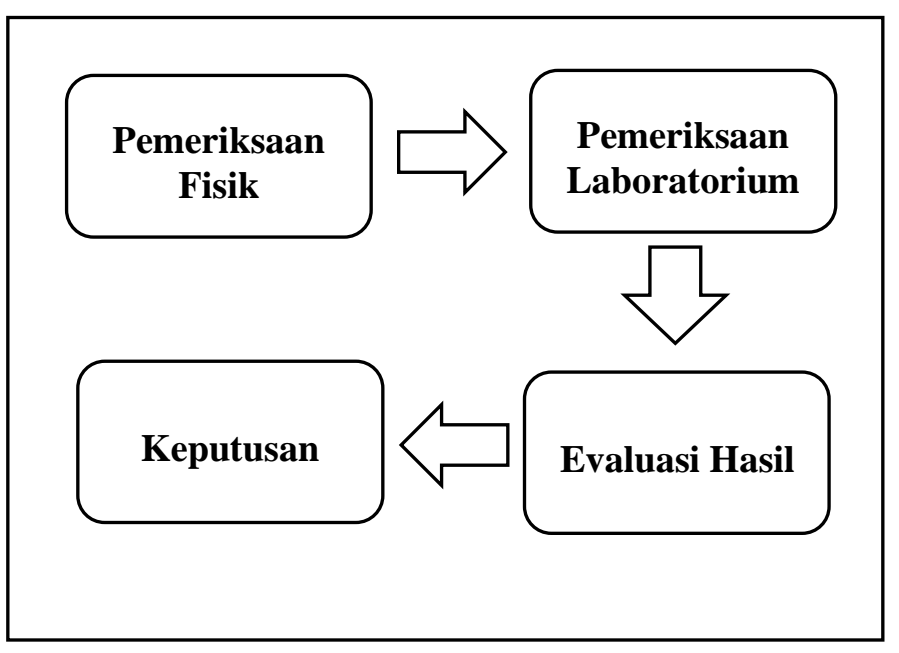

Bagan 1. Alur Pemeriksaan Kesehatan Sebelum Bekerja RSIJPK

b. Pemeriksaan Kesehatan Berkala

Peneliti melakukan telaah dokumen terkait dengan proses pemeriksaan kesehatan berkala. Dokumen yang digunakan sebagai pedoman dalam pelaksanaan pemeriksaan kesehatan berkala adalah Standard Operating Procedures (SOP) pemeriksaan kesehatan. Dalam SOP, terdapat langkah - langkah yang harus dilaksanakan dalam proses pemeriksaan kesehatan berkala.

Berdasarkan hasil wawancara dengan informan kunci, pemeriksaan kesehatan berkala dilakukan selama sekitar tiga hari. Jenis-jenis pemeriksaan yang dilakukan adalah pemeriksaan fisik, rontgen, pemeriksaan urin, dan darah. Untuk pegawai yang termasuk golongan risiko tinggi, terdapat beberapa pemeriksaan tambahan sesuai dengan area di mana pegawai tersebut bekerja. Untuk pegawai yang bekerja di area bising, maka akan dilakukan pemeriksaan audiometri, untuk pegawai yang bekerja di area dengan kadar debu yang tinggi maka akan dilakukan pemeriksaan spirometri. Sedangkan untuk pegawai yang bekerja di area high care maka akan dilakukan tes salmonella.

\section{“... Nah nanti setelah pelaksanaan medical} checkup itu dilakukan, biasanya si pegawai daftar dulu, nanti dikasih label. Kalau misalnya untuk periksa urin dikasih tempat urinnya, nah nanti dia harus menjalani tes darah, ambil darah, ambil urin, kemudian rontgen..."

Berdasarkan hasil wawancara dengan informan kunci, menurut kepala bagian Manris, jenis-jenis pemeriksaan yang dilakukan pada saat penyelenggaraan pemeriksaan kesehatan berkala terdiri dari pemeriksaan fisik, rontgen, dan pemeriksaan laboratorium. Untuk pegawai yang bekerja di area-area tertentu, maka akan diadakan pemeriksaan tambahan seperti audiometri, spirometri, dan tes salmonella untuk pegawai yang bekerja di area high care. 
Berikut alur pelaksanaan pemeriksaan kesehatan berkala RSIJPK tahun 2016:

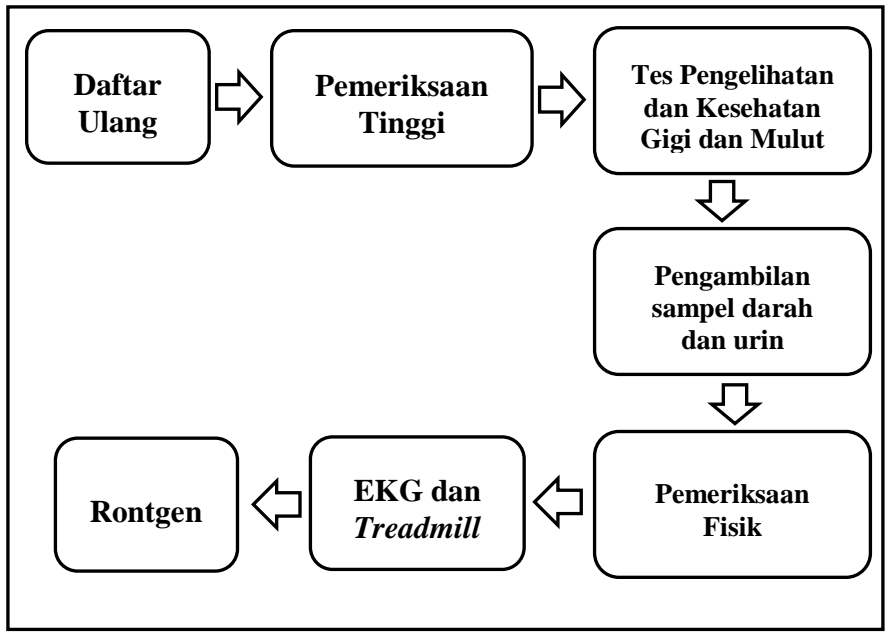

Bagan 2. Alur Pemeriksaan Kesehatan Berkala RSIJPK Sebelum Bekerja RSIJPK

Berikut kutipan hasil wawancara dengan informan utama:

“... Biasanya dari kami yang request karena berpikir perlu. Terus, kemudian, untuk orang-orang yang mungkin pernah sakit hipertensi gitu, biasanya dari kami akan konsultasi dengan dokter, nanti dokter akan kasih usulan ke mana nanti dia akan follow up nya, gitu... kita di sini juga ada voucher berobat ya, biasanya sih pegawai lagsung minta ke klinik terus tinggal berobat..." (SA)

Berdasarkan hasil wawancara dengan informan utama, berdasarkan keterangan dari informan utama, pegawai yang akan melakukan pemeriksaan khusus di rumah sakit terlebih dulu meminta surat pengantar kepada bagian MCU. Selain itu, pegawai juga dapat melakukan pemeriksaan kesehatan dengan menggunakan voucher pemeriksaan yang berlaku di rumah sakit. Berikut kutipan hasil wawancaranya:

“...kalau voucher sih, pegawai minta langsung ke MCU, nanti kita kan juga ada laporannya juga, data pegawai yang periksa..." (NA).

Dalam pemeriksaan kesehatan khusus, berdasarkan hasil penelitian, RSIJPK telah melakukan pemeriksaan kesehatan khusus kepada pegawai sesuai dengan kondisi yang telah ditetapkan dalam Permenaker No. 02 tahun 1980 yaitu apabila tenaga kerja mengalami kecelakaan, tenaga kerja mengalami yang diduga mengalami gangguan dalam kesehatannya. ${ }^{6}$

\section{Output}

Berdasarkan SOP, setelah melakukan pemeriksaan fisik, darah, urin, feses, dan foto rontgen kandidat, bagian MCU dan Manris memeriksa hasil pemeriksaan dan memberikan hasil evaluasi kepada Recruitment Manager di SDI. Setelah itu, bagian SDI memproses tindakan lebih lanjut terhadap pegawai baru yang bersangkutan.

Berdasarkan Permenakertrans No. 02 Tahun 1980 tentang pemeriksaan kesehatan Pasal 3, dalam hal ditemukan kelainan- kelainan atau gangguan-gangguan kesehatan pada tenaga kerja pada pemeriksaan berkala, pengurus wajib mengadakan tindak lanjut untuk memperbaiki kelainan-kelainan tersebut dan sebab-sebabnya untuk menjamin terselenggaranya keselamatan dan kesehatan kerja. ${ }^{6}$ 
Tabel 2. Hasil Penelitian Output Pemeriksaan Kesehatan

\begin{tabular}{|c|c|c|}
\hline $\begin{array}{c}\text { Pemeriksaan Kesehatan Sebelum } \\
\text { Bekerja }\end{array}$ & Pemeriksaan Kesehatan Berkala & $\begin{array}{c}\text { Pemeriksaan } \\
\text { Kesehatan Khusus }\end{array}$ \\
\hline $\begin{array}{l}\text { Hasil pemeriksaan kesehatan berupa } \\
\text { kondisi kesehatan calon pegawai. } \\
\text { Kondisi tersebut sebagai penentu } \\
\text { apakah calon pegawai dapat diterima } \\
\text { bekerja atau tidak. }\end{array}$ & $\begin{array}{l}\text { Hasil pemeriksaan kesehatan berupa status } \\
\text { kesehatan pegawai selama setahun } \\
\text { bekerja. } \\
\text { Jika pegawai mengalami gangguan } \\
\text { kesehatan, maka pegawai akan melakukan } \\
\text { pemeriksaan lanjutan hingga status } \\
\text { pegawai menjadi sehat kembali. }\end{array}$ & $\begin{array}{lr}\text { Hasil } & \text { pemeriksaan } \\
\text { kesehatan } & \text { berupa } \\
\text { kondisi } & \text { kesehatan } \\
\text { pegawai } & \text { setelah } \\
\text { melakukan } & \\
\text { pemeriksaan } & \text { khusus } \\
\text { sesuai } & \text { dengan } \\
\text { permintaan } & \text { pegawai. } \\
\text { Hasil tersebut akan } & \text { dilaporkan } \quad \text { kepada } \\
\text { poliklinik perusahaan. }\end{array}$ \\
\hline
\end{tabular}

Berdasarkan hasil wawancara mendalam, dapat disimpulkan bahwa selama ini hasil pemeriksaan kesehatan berkala untuk pegawai hanya dijelaskan kepada pegawai yang diindikasikan mengalami gangguan kesehatan, untuk pegawai lainnya dapat mengkonsultasikan secara langsung ke dokter. Tindak lanjut dari hasil pemeriksaan adalah jika terdapat pegawai yang mengalami masalah kesehatan, maka pegawai tersebut akan melakukan pemeriksaan lanjutan hingga dokter menyatakan bahwa kondisi pegawai tersebut telah fit.

Output dari pemeriksaan kesehatan berkala bagi pegawai berupa hasil pemeriksaan yang dilakukan oleh pegawai. Berdasarkan hasil wawancara mendalam peneliti tentang hasil pemeriksaan kesehatan, RSIJPK telah melakukan tindakan yang sesuai dengan Permenakertrans No. 02 tahun 1980 tentang pemeriksaan kesehatan dan telah diperinci ke dalam SOP sebagai pedoman teknis untuk pelaksanaan pemeriksaan kesehatan di RS. ${ }^{6}$ Namun, selama ini, hanya pegawai yang terindikasi ada masalah kesehatan yang mengetahui hasil pemeriksaan kesehatan berkala.

Berdasarkan hasil wawancara mendalam, dapat disimpulkan bahwa hasil pemeriksaan khusus adalah untuk mengetahui kondisi fisik pegawai yang diperiksa dianggap tidak fit. Tindak lanjut dari pemeriksaan kesehatan khusus adalah perawatan terhadap pegawai. Hasil pemeriksaan kesehatan khusus ini telah sesuai dengan tujuan pemeriksaan kesehatan khusus yang tercantum di dalam Permenakertrans No. 02 Tahun 1980 tentang Pemeriksaan Kesehatan yaitu untuk menilai adanya pengaruh dari pekerjaan tertentu terhadap tenaga kerja atau golongan-golongan tenaga kerja tertentu. ${ }^{6}$ 


\section{Umpan Balik}

Tabel 3. Hasil Penelitian Umpan Balik Pemeriksaan Kesehatan

\begin{tabular}{|c|c|c|c|}
\hline & & Faktor Pendukung & Faktor Penghambat \\
\hline \multicolumn{4}{|c|}{ 1. Pemeriksaan Kesehatan Sebelum Bekerja } \\
\hline $\mathrm{a}$ & Input & $\begin{array}{l}\text { Sarana dan prasarana yang kurang memadai karena belum ada } \\
\text { klinik khusus }\end{array}$ & $\begin{array}{l}\text { RS belum memiliki klinik } \\
\text { khusus. }\end{array}$ \\
\hline & & $\begin{array}{l}\text { RS telah mengikuti prosedur yang telah ditetapkan dalam } \\
\text { Permenakertrans No. } 02 \text { Tahun } 1980 \text { yang diperinci dalam } \\
\text { SOP }\end{array}$ & \\
\hline b. & Proses & $\begin{array}{l}\text { Kerjasama yang baik antara pihak-pihak terkait baik dari } \\
\text { MCU, Lab, Rontgen, klinik umum, mata, dan gigi. }\end{array}$ & $\begin{array}{l}\text { RS belum memiliki dokter khusus K3 } \\
\text { yang bersertifikasi hiperkes }\end{array}$ \\
\hline c. & Output & $\begin{array}{l}\text { Rumah sakit langsung mendapatkan hasil } \\
\text { pemeriksaan calon pegawai dari bagian Manris yang diterima } \\
\text { dari MCU. }\end{array}$ & $\begin{array}{l}\text { RS belum mengalami hambatan dalam } \\
\text { ketepatan waktu dari hasil pemeriksaan } \\
\text { kesehatan }\end{array}$ \\
\hline 2. & \multicolumn{3}{|c|}{ Pemeriksaan Kesehatan Berkala } \\
\hline a. & Input & $\begin{array}{l}\text { Sarana dan prasarana sudah cukup baik namun belum ada } \\
\text { klinik khusus pemeriksaan kesehatan berkala bagi pegawai. }\end{array}$ & $\begin{array}{l}\text { RS belum memiliki klinik } \\
\text { khusus. }\end{array}$ \\
\hline b. & Proses & $\begin{array}{l}\text { Kerjasama yang baik antara pihak-pihak terkait baik dari } \\
\text { MCU, Lab, Rontgen, klinik umum, mata, dan gigi. }\end{array}$ & $\begin{array}{l}\text { Ada pegawai yang mangkir } \\
\text { dari MCU } \\
\text { Belum adanya dokter khusus K3 yang } \\
\text { melakukan pemeriksaan kesehatan } \\
\text { berkala }\end{array}$ \\
\hline c. & Output & $\begin{array}{l}\text { Hasil pemeriksaan keluar tepat waktu, namun parameter } \\
\text { MCU yang digunakan masih parameter kesehatan umum, } \\
\text { belum berdasarkan K3. }\end{array}$ & $\begin{array}{l}\text { Belum adanya dokter khusus K3 sehingga } \\
\text { tidak ada diagnosis K3 yang dihasilkan. }\end{array}$ \\
\hline 3. & \multicolumn{3}{|c|}{ Pemeriksaan Kesehatan Khusus } \\
\hline a. & Input & $\begin{array}{l}\text { Sarana dan prasarana cukup memadai namun belum adanya } \\
\text { klinik khusus pemeriksaan kesehatan }\end{array}$ & $\begin{array}{l}\text { RS belum memiliki klinik } \\
\text { khusus pemeriksaan kesehatan. }\end{array}$ \\
\hline
\end{tabular}

\section{Lingkungan}

Menurut Silalahi, kekuatan- kekuatan utama di luar organisasi dengan potensial untuk memengaruhi secara signifikan produk atau layanan secara berhasil dinamakan lingkungan eksternal. ${ }^{7}$ Menurut Suhendra, lingkungan eksternal adalah kekuatan-kekuatan utama di luar organisasi yang memiliki potensi untuk memengaruhi keberhasilan suatu organisasi dalam mencapai tujuannya. ${ }^{8}$

Lingkungan eksternal dapat dikelompokkan dalam dua jenis: 


\section{a. Mega environment}

Mega environment adalah kondisi dan kecenderungan umum di dalam masyarakat tempat beroperasinya sebuah organisasi, yang memberikan pengaruh tidak langsung terhadap organisasi.

\section{b. Task environment}

Task environment adalah unsur-unsur luar yang spesifik yang memengaruhi secara langsung sebuah organisasi dalam upaya untuk menjalankan usahanya. Salah satu bagian dari Task Environment adalah lembaga atau badan yang menyediakan jasa/layanan dan memantau kepatuhan terhadap hukum dan peraturan di tingkat daerah atau nasional.

Berdasarkan hasil wawancara mendalam, pihak-pihak di luar RSIJPK yang memiliki pengaruh terhadap proses pelaksanaan pemeriksaan kesehatan adalah Dinas Kesehatan dan Dinas Tenaga Kerja. Dinkes dan Disnaker secara berkala melakukan audit kepada pihak perusahaan terkait dengan pelaksanaan pemeriksaan kesehatan dan izin poliklinik perusahaan. Namun, peneliti tidak mendapatkan informasi secara lebih rinci tentang bagian dari Dinkes dan Disnaker yang terlibat langsung dalam proses pengawasan penyelenggaraan pemeriksaan kesehatan.

\section{Kesimpulan dan Saran}

Dari hasil penelitian mengenai pelaksanaan Medical Check Up (MCU) pada pegawai RSIJ Pondok Kopi, dapat diambil kesimpulan bahwa ada beberapa hal yang menjadi penghambat dalam pelaksanaannya. Adapun penghambat yang dimaksud antara lain adalah:

a. Belum adanya dokter khusus K3 yang melakukan pemeriksaan kesehatan di RSIJPK, yang ada hanya dokter umum, gigi, dan mata yang melakukan pemeriksaan fisik pada pegawai, dikarenakan ada beberapa dokter di RSIJPK yang masih menempuh pendidikan lanjutan sebagai Dokter Spesialis Okupasi. Hal ini belum sesuai dengan Peraturan Menteri Tenaga Kerja dan Transmigrasi No. 02 Tahun 1980 tentang Pemeriksaan Kesehatan dan Pedoman Pelayanan Medik di Klinik dan Perusahaan. ${ }^{6}$

b. Hanya pegawai yang hasil pemeriksaan kesehatannya mengalami masalah saja yang dapat mengetahui hasil MCU, bagi pegawai yang pada saat pelaksanaan MCU tidak mengalami masalah pada hasilnya, tidak diberi tahu bagaimana hasil pemeriksaan kesehatannya secara menyeluruh, hal ini dikarenakan dana yang dikeluarkan akan lebih banyak jika seluruh hasil MCU diberitahukan kepada pegawai.

c. Ditinjau dari segi sarana dan prasarana, belum ada klinik khusus dalam melakukan MCU, selama ini pelaksanaan MCU dilakukan di masing-masing poli terkait. Seperti misalnya apabila ada pemeriksaan mata, maka MCU dilakukan di poli mata. Hal ini dikarenakan pelaksanaan MCU di 
RSIJPK masih sangat komprehensif, pemeriksaan dilakukan secara menyeluruh dan belum berdasarkan parameter okupasi.

d. Masih ada beberapa pegawai yang mangkir dari pelaksanaan MCU di RSIJPK, hal ini dikarenakan beberapa alasan yaitu lupa dan malas melakukan karena mereka merasa bahwa hasil MCU selalu sama setiap tahun, hal ini dapat diatasi apabila adanya parameter okupasi yang dilibatkan dalam pelaporan hasil MCU, sehingga menjadikan para pegawai aware terhadap pentingnya pelaksanaan MCU.

Selain adanya penghambat, peneliti juga mendapatkan beberapa hal yang menjadi pendukung dalam pelaksanaan MCU di RSIJPK, diantaranya adalah:

a. Adanya kerjasama yang baik antara beberapa pihak yang terkait dalam pelaksanaan MCU, yaitu pihak Manris, MCU, Laboratorium, Rontgen, dan polipoli terkait.

b. Pengaturan dalam pelaksanaan MCU oleh RSIJPK cukup baik, dimana pelaksanaannya dilakukan setiap satu tahun sekali bagi pegawai yang memiliki risiko tinggi dan dengan kebijakan pelaksanaannya setiap bulan ulang tahun pegawai yang bersangkutan. Hal ini dianggap sebagai hadiah ulang tahun dari RSIJPK bagi pegawai.

c. Selalu dilakukan evaluasi terhadap hasil MCU oleh pihak Manris dan MCU sebelum diserahkan ke bagian SDI dan pimpinan.
Saran pelaksanaan MCU di RSIJPK kedepannya agar lebih baik:

1. Dokter di RSIJPK yang memiliki sertifikat Hiperkes sehingga dalam mendiagnosa sesuai dengan parameter okupasi.

2. Klinik khusus pelaksanaan MCU dalam melakukan pemeriksaannya jelas dan tidak tercampur antara pegawai dengan pasien.

3. Pemeriksaan kesehatan berkala, disarankan agar seluruh pegawai diberikan hasil dari pemeriksaan sebagai tolak ukur pegawai menjaga kondisi kesehatannya.

4. Ada sanksi tegas yang diberikan bagi pegawai yang mangkir dalam pelaksanaan MCU, supaya mereka lebih aware terhadap pentingnya pelaksanaan MCU di RSIJPK.

\section{Daftar Pustaka}

1. Departemen Kesehatan RI. Keputusan Menteri Kesehatan No.1204/Menkes/SK/X/2004 tentang Persyaratan Kesehatan Lingkungan Rumah Sakit. Jakarta Indonesia.

2. Undang-Undang RI No. 23 Tahun 1992 tentang Kesehatan. 2004. Yogyakarta: Pustaka Widyatama.

3. Departemen Kesehatan RI. Keputusan Menteri Kesehatan No. 1087/Menkes/SK/VIII/2010 tentang Standar Kesehatan dan Keselamatan Kerja di Rumah Sakit. Jakarta Indonesia. 
4. Departemen Kesehatan RI. Keputusan Menteri Kesehatan No. 432/Menkes/SK/IV/2007 Pedoman Manajemen K3 di Rumah Sakit. Jakarta Indonesia.

5. Trisilawati, R. 2006. Faktor-Faktor yang Menghambat Pelaksanaan Program Kesehatan dan Keselamatan Kerja di RSU Dr. Haryanto Lumajang. Skripsi. Universitas Jember.

6. Peraturan Menteri Tenaga Kerja dan Transmigrasi No.Per.02/MEN/1980 Tentang Pemeriksaan Kesehatan Tenaga Kerja dalam Penyelenggaraan Keselamatan Kerja.

7. Silalahi, Ulber. 2011. Asas-Asas Manajemen. Bandung: PT. Refikan Aditama.

8. Ramadhan, Hendra. 2012. Analisis Implementasi Peraturan Daerah Kota Serang No. 02 Tahun 2010 Tentang Pencegahan, Pemberantasan, dan Penanggulangan Penyakit Masyarakat (Studi Kasus Pengemis di Kota Serang). Skripsi. Fakultas Ilmu Sosial dan Ilmu Politik. Universitas Sultan Ageng Tirtayasa Serang. 